\title{
ACESSO À LEITURA E NARRAÇÃO DE CONTOS DE FADAS NA PRIMEIRA INFÂNCIA: IMPLICAÇÕES PARA A FORMAÇÃO IDENTITÁRIA E A CONSTITUIÇÃO DAS CRIANÇAS COMO SUJEITOS SOCIAIS E DE CONHECIMENTO
}

\author{
ACCESS TO READING AND NARRATING FAIRY TALES IN EARLY CHILDHOOD: IMPLICATIONS \\ FOR IDENTITY FORMATION AND THE CONSTITUTION OF CHILDREN AS SOCIAL AND \\ KNOWLEDGE SUBJECTS
}

\author{
Eliziane Gorete Kielb ${ }^{1}$, Ivone Maria Mendes Silva ${ }^{1}$ \\ 1 Universidade Federal da Fronteira Sul (UFFS), Erechim, RS, Brasil \\ eliziane_kielb@hotmail.com; ivonemmds@gmail.com \\ https://orcid.org/0000-0001-6369-0772; https://orcid.org/0000-0002-0058-091X
}

Recebido em 30 jan. 2020

Aceito em 10 abr. 2020

Resumo: O presente artigo tematiza as possíveis influências dos contos de fadas na construção da identidade infantil. Para tanto, baseia-se nos achados obtidos em estudo etnográfico realizado em duas escolas de educação infantil no município de Erechim/RS.Como parte do estudo, foram realizadas entrevistas com duas docentes que atuam na educação infantil com crianças de idades entre 3 a 5 anos, assim como observações da abordagem por elas utilizada ao trabalharem com contos em sala de aula, seguida de conversas em grupo com as crianças sobre o assunto. Os resultados da pesquisa indicam que as possibilidades que o trabalho com contos coloca para a construção de aprendizados pelas crianças, assim como para a formação de suas identidades, podem ser mais amplas ou mais restritas, dependendo, entre outros fatores, da forma como o trabalho com o tema é conduzido pelos professores. A visão que esses profissionais sustentam sobre o papel da literatura na formação das crianças e a forma como traduzem essa visão em um trabalho educativo, fazendo esse universo de referências chegar aos seus educandos, podem gerar ricas oportunidades de fomentar a atividade reflexiva e imaginativa dos sujeitos infantis, suas habilidades em lidar com as próprias emoções, bem com seu repertório cultural.Conclui-se que os professores, ao atuarem como mediadoresna promoção do encontro das crianças com os contos e outras modalidades literárias, podem contribuir decisivamente para o desenvolvimento destas enquanto sujeitos sociais e de conhecimento.

Palavras-chaves: Infância. Identidade. Contos de Fadas. Literatura. Educação Infantil.

\begin{abstract}
This article deals with the possible influences of fairy tales in the construction of children's identity. For this purpose it is based on the findings obtained in an ethnographic study carried out in two early childhood schools in the city of Erechim/RS. As part of the study, two teachers who work in early childhood education with classes aged 3 to 5 years were interviewed, and observations were made regarding the approach they used when working with tales in the classroom, followed by group conversations with the children on the subject. The results of the research indicate that the possibilities that the work with tales poses for the construction of learning by the children, as well as for the formation of their identities, can be broader or more restricted, depending, among other factors, on the way the work with the theme is conducted by the teachers. The view they hold on the role literature plays in the formation of children and the way they translate that view into educational work, making this universe of references reach the children, can generate rich opportunities to foster their reflective and imaginative activities, their skills in dealing with emotions, as well as their cultural repertoire. It is concluded that teachers, when acting as mediators in promoting the encounter of children with tales and other literary modalities, can contribute decisively to their development as social and knowledge subjects.
\end{abstract}

Keywords: Childhood. Identity. Fairy tale. Literature. Child education. 


\section{INTRODUÇÃO}

A relação entre a infância e os chamados contos de fadas é histórica e culturalmente substancial. Ao entrar em contato com um conto, a criança tem a oportunidade de enriquecer sua vida imaginativa, além de trabalhar questões que figuram como desafiadoras para ela tanto na realidade psíquica quanto na relação com o mundo. O processo de identificação com determinados personagens ou algumas de suas ações e valorespodecontribuir para a resolução de conflitos internos que fazem parte do desenvolvimento humano, além de oferecer-lhe referências identitárias importantes para a construção de laços sociais de pertencimento e uma imagem de si alimentada por aprendizados plurais.Quando todas essas possibilidades são reconhecidas pelos profissionais que atuam em contextos escolares, oferecendo aporte ao trabalho educativo por eles desenvolvido, o encontro da criança com o conto pode redundar em resultados surpreendentes para a formação desta enquanto sujeito social e de conhecimento.

O presente artigo apresenta reflexões sobre esse tema, buscando, a partir da revisão da literatura científica especializada, discutir conceitos e contribuições baseadas em estudos empíricos realizados por outros pesquisadores. Além disso, analisa as percepções de professoras que atuam na educação infantil, assim como das crianças com quem trabalham, sobre as possíveis influências que os contos podem exercer sobre a construção da identidade infantil.

A temática dos contos tem sido alvo do interesse de pesquisadores de diferentes áreas do conhecimento: Literatura, Linguística, Educação, Psicologia, Psicanálise, entre outras. Ainda que prolífica e diversificada, essa produção deixa margem para a abordagem, pelos pesquisadores, de muitos recortes temáticos ainda não explorados.Ao investigarmosem outros estudosque focalizam a relação dos sujeitos infantis com os contos (COSTA, 2013; SILVA, 2010; OLIVEIRA, 2010) e a frequência de debates sobre a questão da construção identitária, constatamos que as pesquisas na área pouco abrangem esse tópico, voltando-se mais para o uso dos contos em processos pedagógicos. Alguns estudos (MASSUIA, 2011) investigam as percepções dos professores a respeito dos contos de fadas. No entanto, a maioria enfoca a faixa etária dos anos iniciais do ensino fundamental, ou seja, crianças com idade entre 6 e 9 anos. Apenas um dos trabalhos encontrados (RODRIGUES, 2010) 
abrange a educação infantil, porém o faz focalizando a questão da influência dos contos nas construções de narrativas das crianças. Pouco se estudou, portanto, sobre o tema com crianças pequenas.

Outro aspecto a considerar é a participação das crianças em relação à pesquisa de campo, que também foi pouco explorada nos estudos anteriores.O presente artigo propõe-se a contribuir para o avanço dessa produção, explorando tanto a visão dos docentes, referente à influência dos contos de fadas na construção da identidade infantil, quanto a das crianças entre 3 a 5 anos, ou seja, as duas perspectivas serão analisadas no mesmo estudo, buscando a discussão de casos específicos e contextualizados.

\section{IMPORTÂNCIA DA LITERATURA E DOSCONTOS DE FADAS PARA OS PROCESSOS DECONSTRUÇÃO IDENTITÁRIA NA INFÂNCIA: O LUGAR DA LINGUAGEM IMAGINÁRIA}

A educação e a reflexão sobre os processos educativos não se restringem a uma única área, exploração ou único saber. O universo humano, aqui em específico o universo infantil, é vasto em questões a serem exploradas. O reconhecimento da criança de forma global, como ser ativo, desejante e reflexivo, significa "recebê-la em sua totalidade" (RADINO, 2003, p. 163), tornando possível o desenvolvimento integral do ser humano e o desenvolvimento de um conhecimento significativo.

Ao contar um conto, os diferentes narradores apropriam-se dele de diferentes formas e transmitem significados distintos para os também diferentes ouvintes, 0 que cria elementos a cada narração, a fim de torná-la significativa para aquelas pessoas, naquele momento. Nesse sentido, inconscientemente, o modo como se conta e quem conta influenciam inevitavelmente a compreensão daqueles que terão acesso à história. Para além disso, cabe notar que as crianças tendem também a se identificar com elementos que concretizem suas necessidades e/ou desejos. Ainda que grande parte dos contos de fadas acessíveis a eles na atualidade tenham incorporado elementos relativos às crianças e infâncias de outros tempos e contextos socioculturais, carregam fortes elementos de identificação, ao exporem possibilidades de vivências, bem como de significação e reação a elas, que capturam o interesse das crianças de hoje, ainda mais se narradas de modo envolvente (BETTELHEIM, 2014). 
Não se pode negar que no interior da criança há um universo consciente e inconsciente, que é único e distinto do adulto, pois há nele uma necessidade profunda de fantasia, imaginação. A imaginação desenvolve-se no decorrer de nossas vidas e em diferentes situações. Através dela pode-se vivenciar situações e criar personagens que exteriorizem sentimentos e necessidades internas de cada indivíduo.

A imaginação está ligada não só às emoções, mas, também, à inteligência e é construída e cultivada aos poucos na criança, sendo essencial para seu processo de desenvolvimento. Com a enorme expansão tecnológica, influenciar a imaginação é possibilitar outros meios de interação além da televisão, do computador etc. O contato com a imaginação é algo impalpável, uma exploração que vai além de atos concretos. Imaginação e informação são como uma via de mão dupla, que andam na direção da curiosidade da criança, possibilitando uma "vida imaginativa" afável e substancial, em cujo processo a criança participa de forma ativa. E se há um laço ainda mais importante é o da narração de histórias, já que elas funcionam como fomento para sua subjetividade, constituindo-se uma fonte frutífera para a imaginação (GIRARDELLO, 2011).

A linguagem imaginativa trazida nos contos de fadas faz uma mediação entre a criança e o mundo (RADINO, 2003), criando um cenário para o desenvolvimento da criança em suas diferentes esferas, ao elaborar situações e estruturas que ela, por si só, ainda não tem capacidade psíquica suficiente para fazê-lo. Os contos de fadas trazem explicações e esclarecimentos oportunos à infância, além de servirem como bases para o desenvolvimento da linguagem imaginativa da criança. Esta pode ser influenciada a criar, imaginar, fantasiar, mas, para isso, necessita de bases que antecedem esse processo. Girardello (2011, p. 82) elucida a importância do contato com os contos e outras histórias para a formação estético-literária e o estímulo da capacidade criadora e imaginativa nas crianças:

As crianças têm necessidade das imagens fornecidas pelas histórias como estímulo para sua própria criação subjetiva, para sua exploração estética e afetiva dos meandros do mundo. A necessidade de histórias tem sido identificada como um aspecto central na vida imaginativa das crianças [...]. Isso ocorre tanto em relação aos contos literários quanto aos casos contados no meio das conversas, tão apreciados pelas crianças. Cada uma delas imaginará um pássaro diferente ao ouvir contar $\mathrm{O}$ rouxinol do imperador, de Andersen, e verá cenas mentais únicas ao ouvir o relato das andanças da tia pelo centro da cidade (GIRARDELLO, 2011, p. 82). 
Ou ainda, como expõe Vicente (2010), o "Era uma vez..." transpõe as crianças para outro espaço, e isso é a garantia de que não se trata da sua realidade externa, que pode usufruir da sua imaginação sem nenhum precedente, o que causa a "identificação imediata da criança com o conto" (VICENTE, 2010, p. 48),. Dessa forma a criança está amparada para lidar com seu interior, seus medos, suas angústias e frustrações.

Além disso, a imaginação oferece um suporte preciso para a educação à medida que a própria objetividade se dá por estruturas imaginativas e pela capacidade de construir formas mentais do conhecimento obtido. O que é necessário e comum a todas as áreas é justamente esse "apelo à imaginação" e as capacidades que esta constrói. Uma das capacidades mais importantes, a de deixar suas características de lado, pondo-se e enxergando com o olhar do outro, é o ponto de partida para a compreensão de todo e qualquer saber (EGAN, 2007).

\section{IDENTIDADE E IDENTIFICAÇÃO}

Assim como oser humano é social e histórico, sua identidade também é histórica e socialmente construída, sendo a participação em redes de relações e o acesso a artefatos culturais imprescindíveis ao desenvolvimento de sua singularidade.É somente mergulhado em um mundo de cultura que cada indivíduo pode encontrar e se identificar, quando assim lhe aprouver, com os elementos necessários à composição de sua própria identidade.A identificação pode ser definida, a partir da teoria psicanalítica, como: "processo psíquico através do qual um sujeito assimila características do outro, adotando-o como modelo e transformando-se. A personalidade se constitui por sucessivas identificações" (LAPLANCHE; PONTALIS, 1985, p. 292).

De acordo com Corso e Corso (2006), descobrimo-nos no outro, e isso torna a tarefa de termos nossa própria identidade ainda mais difícil e geradora de confusões entre os limites do eu e do outro. A identificação nesse aspecto é mais do que diz seu nome; o outro faz parte da nossa construção, tem tarefa fundamental na constituição do nosso ser, ou seja, é peça importante e insubstituível na nossa existência. 
Desde bem pequenos, vivemos relações com o meio e com as pessoas que se tornam significativas para aspectos da construção das nossas identidades. Moreno (2014, p. 105) refere o conceito de "ego auxiliar", defendendo que, durante a infância, a criança precisa de "egos auxiliares", os quais, inicialmente, são seus pais, pelas necessidades do bebê que precisam ser supridas. Eles também são responsáveis pela sua inserção e seus primeiros contatos com a cultura e os grupos sociais.

O ego auxiliar ajuda nas funções que a criança ainda não tem autonomia para realizar, representando-a, orientando-a e auxiliando-a. A identificação é um processo complexo, que a criança vai conquistando com seu esforço pelo desejo de identificar-se com algo ou alguém externo ao seu ego (MORENO, 2014). Aos poucos a criança vai se desenvolvendo e criando mais autonomia e independência em relação ao seu ego auxiliar. Esse primeiro processo também é considerado por Moreno (2014, p. 114) como uma "matriz de identidade", que vai ser responsável pelas suas primeiras ações, dando segurança para o desenvolvimento da sua independência.

O primeiro contato com a cultura, nesse sentido, dá-se a partir das primeiras matrizes de identidade e, ao longo da vida, vai se expandindo para a escola, para os grupos de convivência e para outras referências. É com o apoio dos egos auxiliares que a criança se insere na cultura e, através das referências por eles providas, pode construir suas experiências de vida com mais segurança, criando formas de identificação que lhe são próprias, as quais darão origem à sua identidade.

Os livros são artefatos substanciais da cultura e, sendo assim, a literatura torna-se uma referência importante para a formação do ser humano integral. Os contos de fadas em específico são ainda mais ricos nesse sentido, pois são como "espelho da experiência interior da criança" (VICENTE, 2010, p. 23). Além disso, de acordo com Corso e Corso (2006), a literatura constata realidades internas muito antes do que qualquer tipo de ciência possa descrevê-las e explicá-las. Ou seja, a literatura tem a capacidade de antecipar conhecimentos. A fase em que a criança ingressa na escola pode ser considerada uma das mais decisivas para seu desenvolvimento, pois nela diversas coisas surgem como novidades desafiadoras e um universo de escolhas se inicia. Os contos de fadas são como uma preparação psicológica para lidar com isso. 
Segundo Radino e Oliveira (2009), os contos de fadas são importantes auxiliadores, na realidade psíquica, para compreender e enfrentar angústias, governar os desejos e sonhos por meio da criação de imagens que os representem. As autoras em questão reconhecem a importância dos contos de fadas para a realidade psíquica das crianças, dizendo que os contos de fadas são"metáforas de processos que elas vivem inconscientemente" (RADINO; OLIVEIRA, 2009, p. 29), onde é possível "compartilhar angústias e desejos sem sentirmos culpa" (RADINO; OLIVEIRA, 2009, p. 29). Desenvolvendo essa discussão, as mesmas autoras ainda questionam:

O que a leitura ou escuta de uma história ou um filme poderiam representar? Justamente uma identificação, através da transferência, de experiências de outras cenas que a vida não possibilita. Os contos, o cinema e outras obras artísticas criam outras cenas que sustentam a vida imaginária (RADINO; OLIVEIRA, 2009, p. 32).

Esses artefatos da cultura são imprescindíveis para o mundo simbólico da criança, possibilitando o reconhecimento de sonhos, desejos, angústias e traumas, proporcionando momentos de reflexão e crítica particular sobre esses sentimentos ou simplesmente vivenciando sentimentos necessários para seu desenvolvimento enquanto sujeitos (RADINO; OLIVEIRA, 2009).

Unindo todos esses referenciais, percebemos que o professor pode transpor os contos de fadas para sua prática na escola, lugar de diversidade, de construção, não só do conhecimento, mas do ser humano em sua totalidade. Assim, possibilitando que a criança possa lidar com suas angústias, emoções e diferentes sentimentos que permeiam seu interior, identificando-se e transportando sentimentos para diferentes situações e personagens, de acordo com suas necessidades e preferências.

\section{PERCURSO METODOLÓGICO}

Esta pesquisa tem uma abordagem qualitativa, uma vez que focaliza o tema estudado sem perder de vista sua amplitude e a variedade de pontos de vistaque podem existir sobre ele, buscando acessar os significados subjetivos a eles relacionados (FLICK, 2009). Nesse tipo de abordagem, o pesquisador é visto como uma parte importante do processo de pesquisa, constituindo-se ser ativo e social. 
Com isso, quando imerso em uma realidade, leva partes de sua subjetividade para ela, direcionando-se a partir de sua particularidade, para algo a ser estudado em outra realidade, de forma a investigar e ampliar seus horizontes e os horizontes da pesquisa (FREITAS, 2007).

O trabalho foi realizado em duas etapas. A primeira, de base teórica bibliográfica, aborda conceitos e discussões atuais sobre o tema descrito. $\mathrm{Na}$ segunda, foi realizada uma pesquisa de campo de cunho etnográfico, com duas turmas de educação infantil, de escolas distintas, do município de Erechim-RS. Por meio da realização de entrevistas e observações, buscou-se investigar as percepções tanto das crianças, quanto dos professores, em relação aos contos de fadas e suas possíveis influências sobre a construção identitária das crianças e a constituição destas como sujeitos sociais e de conhecimento. Neste estudo, a observação foi feita no dia em que as docentes participantes da pesquisa realizaram o trabalho com o conto de fadas, com a duração de aproximadamente duas horas. Para registro das observações, foi utilizado um diário de campo, voltando o olhar para as questões centrais que se pretendia analisar e procurando registrar diferentes aspectos relevantes na compreensão dos acontecimentos, incluindo descrições, reconstruções de diálogos, esclarecimentos e reflexões das pesquisadoras (LUDKE; ANDRÉ, 1986).

Um dos cuidados éticos adotados nesta pesquisa foi o emprego de nomes fictícios para designar crianças, professoras $e$ as escolas nas quais estudam/trabalham, de modo a preservar suas identidades ${ }^{1}$. As duas escolas pertencem à rede pública de ensino e encontram-se em bairros periféricos da cidade, atendendo crianças das camadas populares, desde a educação infantil até o ensino fundamental.

As crianças envolvidas na pesquisa compõem duas turmas de Educação Infantil, uma delas de Pré $A$, com idades entre 3 a 4 anos, e outra de Pré $B$, com idades entre 4 e 5 anos. A turma de Pré A, da Escola Municipal de Ensino Fundamental Flor de Sal, tem 16 crianças matriculadas, sendo 9 meninos e 7 meninas. A professora, Maria, que trabalha nesta escola, tem 31 anos e é licenciada em Pedagogia, pela Universidade Federal da Fronteira Sul (UFFS). Sua atuação

\footnotetext{
${ }^{1}$ Para a realização da pesquisa, foi solicitado aos pais um termo de consentimento, inclusive para uso das produções orais das crianças em publicações.
} 
com a turma analisada ocorre há um ano. Atualmente está cursando Mestrado em Educação pela UFFS - Campus Erechim.

A turma de Pré B, da Escola Municipal de Ensino Fundamental 10 de Novembro, é composta por 21 crianças matriculadas, sendo 10 meninos e 11 meninas. Tem a professora Mariana como docente. Ela tem 32 anos e é formada em Pedagogia, pela Universidade Regional Integrada do Alto Uruguai e das Missões (URI). Tem Mestrado em Educação pela Universidade de Passo Fundo (UPF) e atua como professora há nove anos nessa escola e há dois anos com turma de Pré $\mathrm{B}$.

As professoras participantes da pesquisa foram escolhidas pela sua área de atuação e disponibilidade em participar do estudo. Ao propor a pesquisa, mencionamos o interesse em observar como elas construiriam, junto a suas turmas, um trabalho com contos de fadas. Ao aceitarem, elas apresentaram seu próprio planejamento, tendo a professora Maria escolhido trabalhar com o conto clássico Chapeuzinho Vermelho, de Charles Perrault (1967), enquanto a professora Mariana optou pelo conto contemporâneo Ervilina e o Princês, de Sylvia Orthof, releitura de $A$ princesa e a ervilha, escrito por Hans Christian Andersen.

\section{RESULTADOS E DISCUSSÃO}

As contribuições de um trabalho com os contos de fadas para a constituição identitária das crianças foram destacadas pelas professoras participantes desta pesquisa nas entrevistas por elas concedidas, assim como nas observações emomentos de diálogo com as crianças, caracterizando essas contribuições como associadas à intervenção pedagógica, ou seja, possíveis de mediação. Nesse sentido é que podemos afirmar que nossos achados corroboram a compreensão de que:

Sem dúvida a formação da Identidade é um problema educacional, principalmente quando se entende que ninguém nasce com a própria identidade definida. O se conhecer a si mesmo é uma tarefa complexa que exige a cooperação de muitas pessoas. (LINS, 2009, p. 641)

Levando em conta a complexidade dessa construção, com o passar do tempo muitas pessoas fazem parte e contribuem no processo de construção de identidade. Como defendido anteriormente, esse processo é passível de mudanças e vai se constituindo ao longo do tempo. As matrizes de identidade que nos são oferecidas 
exercem grande influência sobre essa construção, assim como as mediações acessíveis ao longo do processo também nos oferecem modelos identitários que nos influenciam.

Um dos fatores substanciais para a construção da identidade dos sujeitos é o estímulo à imaginação. A linguagem imaginativa trazida nos contos de fadas é uma ferramenta na busca de conhecimentos - objetivos e subjetivos. Por meio dessa linguagem é possível criar laços de identificação com aspectos do nosso ser, da nossa realidade, ampliando a visão que se tem do imediato, trazendo novas possibilidades, questionando o real por meio da fantasia, tornando-a uma fonte de reflexão e apropriação de novos conhecimentos.

O trabalho com os contos apresenta diferentes explorações e amplificações. Um dos fatos percebidos a ser considerado nas observações foram as produções de narrativas pelas crianças. $O$ contato e a vivência com os contos fazem com que a criança se aproprie daquela narrativa tomando-a como referência para construção de suas próprias. Essa ampliação do repertório e das narrativas culturais é uma referência fundamental no desenvolvimento infantil. $O$ domínio da linguagem vai sendo apropriado aos poucos pela criança e muito influenciada pelos estímulos que recebe.

Nos relatos das crianças foi possível observar que elas se apropriam da linguagem dessas histórias quando vão falar delas ou criar suas próprias narrativas. Ao passo que desenvolve a linguagem, o contato com o ouvir histórias gera uma aproximação com diferentes narrativas. No contexto das histórias, nos diálogos, a criança enxerga algumas possibilidades e formas de posicionar-se, de dialogar. E isso acaba influenciando quando as crianças criam suas próprias narrativas, em uma conversa com um colega, em sala de aula ao falar sobre o conto que acabou de ouvir, quando reproduzem a história em suas brincadeiras, entre outras situações.

Nessas construções, segundo Girardello (2007), existem dois modos de pensamento: um modo lógico, que é mais sistêmico, organizacional, de explicações e ordenamentos; e o modo narrativo, que é mais contextual, rico em significado e aspectos da apropriação linguística particular. Nesse sentido, a autora destaca a importância das histórias: papel de mediação entre o mundo imaginário e o contexto próprio das crianças. 
Dessa forma, a capacidade narrativa é um importante aspecto a ser enriquecido com os contos de fadas, narrando-os de diferentes formas, com o livro, com imagens ou sem, contando de forma oral, com características específicas daquele contexto, situações que aconteceram nas observações e que foram ricas em aspectos de narração em ambos os casos.

Foi possível perceber, ao longo da pesquisa, que há uma incorporação de expressões no vocabulário das crianças. Quando referindo-se a uma história que Ihes foi contada, elas lembram aspectos de outra, tecendo também, algumas vezes, associações com aspectos de suas vidas cotidianas. Como no caso do relato de Pedro, da turma do Pré $A$, da professora Maria, referindo-se à história da Chapeuzinho Vermelho:

A chapeuzinho se encontrou com o lobo mau e dai ele disse "vai por outro caminho chapeuzinho" e ele disse o caminho mais longe e ele foi primeiro (expressão de assustado) e pegou a vovozinha, o nariz dele vai crescer! (Relato, entrevista com as crianças, 2016).

Para construir suas narrativas, as crianças baseiam-se em experiências anteriores, nas relações com adultos e com o meio social em geral. No contato com outras histórias, elas apropriam-se de aspectos narrativos que são utilizados em suas falas futuras, processo esse que vai se desenvolvendo aos poucos, desde o nascimento. Sendo assim, "nunca é cedo demais para começar a contar histórias para crianças" (GIRARDELLO, 2007, p. 54).

Ouvindo histórias das mais diferentes formas, as crianças aprendem a "tecer narrativamente sua experiência, e ao fazê-lo vão se constituindo como sujeitos culturais" (GIRARDELLO, 2007, p. 55). Ou seja, por meio dessas experiências as crianças vão criando expressões linguísticas e constituindo-se enquanto narradores de histórias e de suas histórias.

Corroborando essa perspectiva, Rodrigues (2010) afirma que a capacidade narrativa se desenvolve em um ambiente que é estimulador, no qual a criança tem a oportunidade de escutar narrações, mas também de produzir as suas, de maneira livre e autônoma. Para ele, a capacidade narrativa também é um importante meio de reconhecimento do eu, estando vinculado a outrashabilidades, como a de descrever o que se quer, a capacidade de comunicar-se, favorecendo a autonomia. A partir disso, conclui-se, então, que ouvir histórias contribui para a construção de boas narrativas. 
Outras dimensões importantes da identidade são as ações que a criança constrói na relação com o mundo, e as emoções que acarretam parte importante de seu desenvolvimento. Manifestações de ambas as dimensões puderam ser observadas em muitos momentos durante a pesquisa. As emoções foram notadas nas reações das crianças ao entrarem em contato com cada história, ainda durante o trabalho de narração conduzido pela professora, e, posteriormente,envolvendo os momentos de trocas dialógicas com a turma, nos quais podiam expressar suas percepções sobre como receberam as histórias.Por meio de suas ações, as crianças também demonstram suas emoções, estando essas duas dimensões significativamente ligadas. Assim, emoções como alegria, medo, euforia, alívio, surpresa eramdemonstradas através de sorrisos, expressões faciais e vocais, gestos com os braços ou mãos emuitas interjeições ("oh", "éh”, "ahhh”,"ufa!", "que?”, dentre outras). Em alguns momentos, as crianças também se envolviam, a partir das interações umas com as outras, em brincadeiras e breves encenações criadas por elas a partir da história ouvida, colocando em perspectiva possíveis papéis que elas poderiam experimentar ao darem forma às suas fantasias e emoções.

Em entrevista, foi perguntado às docentes como elas percebem a influência dos contos na construção da identidade das crianças. Maria, ao responder, citou que "eles reproduzem aquilo que foi dito na história, até na forma do comportamento deles" (Maria, entrevista 1, 2016).

Esta professora também explicou que, em suas brincadeiras e ações do dia, a dia, as crianças interpretam a história de alguma forma, "quando alguém faz algo errado nas brincadeiras eles falam: vou chamar o lobo pra te pegar" (Maria, entrevista 2, 2016). Citou também um exemplo de uma das brincadeiras no parque em que "um deles era o lobo, então ele assumia, ele botava medo nos outros, dai ele brincava apontava com o dedo 'se vocês não abrirem a porta' era os três porquinhos, 'se vocês não abrirem a porta eu vou assoprar' (risos) reproduziam a história, né" (Maria, entrevista 1, 2016).

$\mathrm{Na}$ turma de Pré A, da professora Maria, muitas crianças gostam e se identificam com o personagem do lobo em Chapeuzinho Vermelho, como citado no exemplo da reprodução da brincadeira das crianças, sendo uma característica da turma em geral. O que ficou evidente nas narrativas das crianças "O lobo mau é igual eu, parece. Eu pego as criancinhas pra fazer um pouco de mingau, mas minha 
mãe não deixa" "Eu acho o lobo muito esperto" (relato, entrevista com as crianças, 2016).

Com os estudos referentes à psicanálise emerge o entendimento que a criança não tem somente pensamentos amistosos (conforme a visão que concebe a infância como o tempo da bondade e da inocência apregoa), mas que sua imaginação pode ter traços hostis, violentos, agressivos, que, às vezes, a deixam inquieta. Há uma preocupação histórica em amenizar a figura do monstro, não mostrando às crianças esses sentimentos, mas isso só faz impedir que a criança tenha experiências em que aprenda a lidar com eles, recursos que a ajudam a enfrentar seus medos e monstros (BETTELHEIM, 2014).

Cabe destacar que essa imagem de inocência, bondade e pureza atrelada às crianças, muito difundida no imaginário social moderno, foi fortemente influenciada pela visão de infância construída na modernidade a partir do surgimento do "sentimento de infância" (ARIÈS, 1981, p. 99), com a criança sendo vista como um ser a ser protegido e preservado. Assim, alguns temas como a morte, recorrente nos contos de fadas, causam estranhamento quando propostas na discussão com crianças. Kirchof e Silveira (2018), no estudo intitulado "O pato, a morte e a tulipa Leitura e discussão de um livro ilustrado desafiador com alunos dos anos iniciais", reportam a experiência realizada com uma turma de $4^{\circ}$ ano de uma escola pública a partir da leitura do livro. Os autores enfatizam que, por meio da leitura da obra com as crianças, foi possível que elas desconstruíssem estereótipos referentes ao tema da morte, bem como elementos dessas representações, construindo novos significados.

É o desconhecimento do universo infantil, por parte do adulto, que acaba privando as crianças desses recursos da fantasia. $O$ inconsciente infantil é repleto de conflitos, sendo "a fonte de matéria-prima e a base sobre a qual o ego erige o edifício de nossa personalidade" (BETTELHEIM, 2014, p. 175), sendo sustentado por meio de fantasias, sem as quais a criança fica sem recursos para enfrentar seus dilemas. Os contos de fadas apontam caminhos e direções possíveis, mostrando que outros podem sentir o mesmo que ela, que existem esses sentimentos para além dela, torna-se um meio de lidar com suas angústias (BETTELHEIM, 2014).

$\mathrm{Na}$ entrevista final, ao ser questionada sobre como percebeu as influências dos contos na identidade das crianças, a professora Mariana relatou acreditar que a 
história narrada, no contexto do trabalho que faz com os contos, repercutiu de forma muito positiva na turma. Isso porque oportunizou muitos debates entre as próprias crianças, que conversavam sobre suas percepções e, a partir disso, puderam adquirir mais autonomia em suas ações. Ela destacou ainda o surgimento, entre algumas crianças, de uma identificação com a atitude da Ervilina em ir cuidar do seu rebanho e recusar a casar-se com o príncipe. "Estão mais autônomas brincam e são várias coisas diferentes [...] com brincadeiras que não necessariamente é casar e ter filhos, [...] de um modo geral não sinto mais elas frágeis, são mais donas de si, acho isso muito interessante" (Mariana, entrevista 2, 2016).

Nos primeiros anos de vida, as crianças aos poucos constituem-se como indivíduos, descobrem suas ações, movimentos de interações com os meios, sendo uma fase de descobertas de emoções significativas. A maneira com que essas descobertas são vistas pelos adultos e como eles reagem a essas demonstrações é primordial ao desenvolvimento da criança. Crianças pequenas são capazes de vivenciar uma diversidade de emoções em um curto período; no entanto, não quer dizer que elas compreendam e reflitam sobre todas elas. Mais especificamente entre os 3 a 6 anos, as crianças vivem muitas experiências sobre o sentir essas emoções, porém a expressão, o diálogo sobre elas, pensar suas consequências não são processos que irão acontecer sozinhos, espontaneamente. As relações e as mediações sociais, incluindo aquelas nas quais estão envolvidos os professores, são determinantes nesse sentido (PANIAGUA; PALACIOS, 2007).

Portanto, o modo como o docente enxerga e maneja essas situações é determinante. A forma como ele se posiciona face as atitudes das crianças, seja prestando atenção, corrigindo, repreendendo ou elogiando, tende a marcar de alguma forma a aprendizagem que a criança constrói sobre a situação por ela vivenciada. Os contos, nesse âmbito, são intermediadores do processo, proporcionando situações ricas e experiências possíveis de mediação:

O jogo simbólico e as experiências vicárias por meio de histórias e contos nas quais os protagonistas vivem situações que os afetam, ou conseguem alegrar os outros ou fazê-los sofrer com sua conduta também são contextos privilegiados para a influência educativa sobre esses aspectos (PANIAGUA; PALACIOS, 2007, p. 74).

Os contos de fadas e as explanações e mediações possíveis de serem feitas a partir do trabalho com eles trazem experiências necessárias à infância, marcando 
significativamente esse período. Baseando-se na atitude de um personagem, a criança poderá problematizar suas próprias ações, identificando-se com ele ou refletindo sobre as escolhas e ações por ele protagonizadas, com o apoio fundamental do mediador. Isso dá às crianças oportunidades de refletirem sobre quem elas são ou gostariam de ser, mobilizando aspectos de sua própria construção identitária, ao influenciar o modo como constituirão traços de si.

Para que essa mediação se concretize, é preciso que haja intencionalidade, que o mediador conheça e reconheça a importância da exploração, que seja recíproca, aceita por ele, mediador, e pelas crianças, e que traga sentido aos questionamentos destas, fazendo-as considerar a possibilidade de ampliarem suas próprias visões de mundo. Nesse caso, a mediação não se restringe somente ao professor, podendo a família e outros agentes sociais exercerem um papel significativo na aproximação que as crianças podem ter a chance de alcançar em relação a esse universo (SIQUEIRA, 2013).

As crianças aprendem aos poucos pelas explorações próprias e pelas mediações sociais a que têm acesso. Isso não é diferente quando se trata dodesenvolvimento da conduta moral. A partir dos 2 anos, aproximadamente, a criança já tem noção de que existem condutas proibidas, desautorizadas, entendendo o que a sociedade na qual se insere (personificada na figura de seus pais ou outros educadores, por exemplo) consideram como errado ou inapropriado (PANIAGUA; PALACIOS, 2007). Assim, quando elas se identificam com personagens que retratam essa possibilidade de transgressão, como no caso do menino que se identifica com o personagem do lobo (mencionado anteriormente), têm ideia do que isso representa para o outro social, ao mesmo tempo em que buscam dar vazão às suas necessidades de expressão emocional, afirmação da identidade e compreensão das normas sociais.

Foi possível identificar muitos momentos em que as crianças expressaram identificação com a história e os personagens, tanto nas observações que realizamos das atividades feitas em sala de aula, como durante os momentos de interação direta com elas, em que foram feitas algumas perguntas específicas sobre a forma como estavam percebendo a história e a atividade de maneira geral. 
Na observação realizada na turma de Pré B, da professora Mariana, pode-se perceber que o final da história gerou muitas opiniões entre as crianças. Após contar a história a professora ia mediando o debate:

Prof. - Mariana: E fim da história.

Joana: Ufa! (Outras crianças batem palmas, como forma de agradecer e mostrar que gostaram) Prof. ${ }^{a}$ Mariana: Por que ufa Joana? Não gostou dessa história?

Joana: Não gostei dessa história profe!

Prof. ${ }^{\text {a }}$ Mariana: Por que você não gostou Joana, o que você achou que tinha que ser diferente? Joana: Deveria ter uma princesa como nos filmes!

Pedro: Eu gostei que o príncipe disse um verso e foi embora! (Algumas crianças disseram "eu também!")

Camila: Eu achei legal a parte da pedrinha lascada embaixo do colchão.

Prof. ․ Mariana: Alguém mais acha que algo deveria ser diferente nessa história?

João: Acho que ela não deveria ir embora, devia se casar com o príncipe.

Marcos: e fazer três filhos! (Completou) (Relato, observação, 2016).

Nessa descrição foi possível perceber que as crianças tiveram espaço, atenção e liberdade para compartilharem suas opiniões a respeito da história narrada, bem como manifestar-se a respeito de terem gostado ou não da mesma, opinando sobre como achavam que deveria ser, o que poderia ter acontecido de diferente. Essa abertura e abordagem da professora Marianapossibilitaram às crianças atribuírem sentido ao conto a partir de suas próprias reflexões. Ao mesmo tempo, foram essas reflexões comunicadas pelas crianças que apontaramdireções para a mediação feita peladocente que, de forma muito sensível, enxergou o quão rico pode ser o processo educativo no qual as crianças podem ter voz e vez no diálogo com seus mestres.

A história Ervilina e o Princês também gerou muitas opiniões a respeito do seu final, quando as crianças assumiram seus ideais no momento de dizer o que fariam, ou quem seriam.

\footnotetext{
Entrevistadora: Você gostaria de ser alguém dessa história?

Renata: Eu queria ser a pastora!

Entrevistadora: O que você ia fazer se fosse ela?

Renata: Eu ia cuidar das ovelhas!

Entrevistadora: E o príncipe que você ia fazer com ele?

Renata: la deixar ele. Eu gosto de cuidar dos animais, é bem melhor do que casar com alguém (Relato, entrevista com as crianças, 2016).
}

Partindo dessas situações, há outras direções possíveis de serem exploradas, em que a criança mesma está oferecendo sua disponibilidade de escuta e curiosidade. Nas falas das crianças, é possível perceber que elas estão expondo 
uma questão dos seus ideais de valores, de vida, de como elas acreditam que deveria acontecer uma relação amorosa, ou não acontecer, visões de identidade de gênero e relacionamentos.

Com todas essas questões, o professor pode mediar esse encontro entre a criança e a literatura, contribuindo para a construção de reflexões sobre os valores que aprendeu com a sua cultura até agora e problematizando-os para construções reflexivas a respeito de sua própria identidade, adquirindo novas visões sobre esses valores sociais.

Tomando como exemplos os dois excertos citados anteriormente, tanto o referente ao relato de observação quanto o da entrevista com as crianças, poderiam ser problematizadas questões como: Vocês falaram sobre essa questão de casar ou não, de casar ou ter uma profissão. O que pensam sobre isso? Quais outras coisas podemos fazer em nossas vidas? O que vocês desejam para a vida de vocês? 0 que acham que as nossas vidas têm de diferente e de semelhante à vida dos personagens da história que acabamos de ouvir? Nesse sentido, podemos discutir com as crianças as relações possíveis entre os personagens e a trama, colocandoas como protagonistas na construção de suas próprias visões a respeito dos valores sociais. Maia, Leite e Maia (2011, p. 150-151) exploram essa questão afirmando que,

\begin{abstract}
A discussão das histórias não deve ser guiada moralmente pelo educador, mas pode ser debatida, discutida, construída. Portanto, a educação deve direcionar os sujeitos a pensar por si mesmos e a colocar-se no lugar do outro, a fim de que eles encontrem maneiras saudáveis, sociavelmente aceitas de realizar seus desejos, podendo renunciar a parte destes em prol da coletividade, ou seja, seguindo as regras sociais por compreender a necessidade destas, por meio da reflexão e construção de pensamento e leitura crítica da realidade.
\end{abstract}

Por meio de intervenções, o professor pode possibilitar que as crianças não apenas se expressem, mas que reflitam sobre esses ideais e valores, tornando a escola, os processos educativos e as relações presentes no cotidiano escolar referências e modelos identitários diferentes ou problematizadores dos que já possuem ou estão assimilando do seu grupo social, grupo de convívio familiar ou até as mídias àsquais têm acesso habitualmente. Um trabalho desse tipo pode ajudar a criança a adotar uma postura crítica face à sua própria realidade, fornecendo-lhe instrumentos que a ajudarão a constituir-se como sujeito social e de conhecimento.

O período da Educação Infantil engloba anos cruciais do desenvolvimento da criança, uma vez que é nesse período que se iniciam as indagações e 
interpretações a respeito das situações que ocorrem ao seu redor, bem como o efeito de suas ações e reações no meio do qual faz parte. A mediação a partir dos contos deve explorar os questionamentos das crianças, ampliando suas percepções e seu contato com o mundo social, criando "contextos em que sua expressão seja mais provável" (PANIAGUA; PALACIOS, 2007, p. 80).

Dessa forma, constrói-se uma relação de proximidade entre professor e aluno, dando segurança para as reflexões por parte das crianças sobre seus ideais, vontades e desejos, consolidando uma formação crítica, baseada no diálogo aberto e franco.

A maneira como o docente lida com essas questões emergentes dos contos de fadas trará ou não experiências significativas para as crianças, a depender dos meios pelos quais proporciona essas experiências e contato com os contos. Em entrevista, as docentes foram questionadas no sentido de saber no que elas se baseiam para selecionar um conto. Uma das respostas diz ser "Na mensagem que existe por trás do conto. Na lição que eu quero passar pra eles" (Mariana, entrevista 1, 2016).

A entrevistada mostra uma intencionalidade de trabalhar questões da educação moral das crianças por meio do conto de fadas, tomando como possibilidade extrair do conto uma lição de moral. É preciso refletir sobre esses aspectos no sentido de discorrer sobre a superficialidade de enfatizar a punição, restringindo as possibilidades que o conto oferece, sem pensar em um processo reflexivo mais complexo.

Percebe-se que é muito frequente os professores privilegiarem situações em que sejam trabalhadas lições de moral em detrimento ao fomento das reflexões a partir dos valores e percepções que as crianças anunciam, deixando escapar oportunidades de serem trabalhadas questões do interesse dos estudantes e pertinentes à sua formação integral enquanto sujeitos sociais e cidadãos. São escolhas, possibilidades que mostram a intencionalidade educativa de cada professor. Mas tais escolhas devem ser colocadas em perspectiva e sopesadas.

Para que o emprego desse recurso não redunde empobrecido, é pertinente a abertura de espaço para a participação das crianças, baseada na sua consideração como sujeitos produtores de conhecimento. Isso inclui a criação de condições 
favoráveis à livre expressão de opiniões a respeito dos temas cuja discussão é suscitada pelos contos. A mediação deve ser construída sobre essas bases.

\section{CONSIDERAÇÕES FINAIS}

O estudo realizado buscou delinear as influências que os contos de fadas exercem sobre a construção da identidade infantil. Para tanto, foram analisadas as percepções de duas docentes sobre o tema, dialogando com o contexto em que atuam, registrando aspectos do trabalho realizado por cada uma delas em suas turmas. Além disso, buscamos identificar essas influências considerando também a perspectiva das crianças, observando suas reações durante o trabalho desenvolvido pelas professoras e dialogando diretamente com elas ao longo do processo de pesquisa. Por meio das observações e entrevistas foi possível constatar a importância dada pelas docentes à linguagem imaginativa como instrumento insubstituível na formação humana, destacando-se as qualidades literárias do conto e o envolvimento que as crianças demonstram com esse tipo de linguagem.

Para além dessas importantes reflexões, com as observações e interações com as crianças, foi possível analisar algumas das influências que os contos de fadas exercem em diferentes dimensões da identidade dos sujeitos, demonstrando com exemplos reais as contribuições possíveis do trabalho com os contos de fadas. Trabalho esse que pode ter diferentes amplitudes e dimensões, dependendo dos aspectos da mediação feita pelo docente em sala de aula. Essa mediação, por sua vez, diferencia-se pela visão que ele tem sobre os contos e sobre a infância, assim como de suas experiências com a literatura, podendo alcançar possibilidades mais amplas ou restritas no que se refere às repercussões do trabalho junto às crianças.

Ao iniciar a leitura de um conto, abrem-se inúmeras possibilidades: o encontro com outra realidade, outro contexto, outros olhares (reais ou não); a identificação com o personagem, a situação, as ações ou o sentimento; os exemplos de narrativas dadas; as discussões que emergem referentes à moralidade ética; os ideais e valores de vida apresentados naquele contexto, que podem ser discutidos com as crianças; e as emoções que estas vivenciam nesse momento, provocadas pela linguagem imaginativa dos contos ou mesmo pela identificação com os personagens e as tramas em que se envolvem.Quando uma criança se identifica 
com algo, com alguma situação ou personagem, podemos reconhecer essa situação como uma oportunidade para problematizar e discutir, fazendo-a refletir sobre aquilo. Por meio do acesso à leitura e narração de contos de fadas, as crianças podem vivenciar diversas experiências, revelando a importância, social e de formação, da literatura no desenvolvimento dos sujeitos em sua integralidade.

Reconhecendo a fecundidade dos contos e da literatura em geral como recursos que podem ser utilizados em prol não apenas da escolarização, mas também da construção da identidade pessoal e social das crianças, o professor pode planejar um trabalho que faça a riqueza de possibilidades contida nesse universo chegar às crianças por meio da mediação.

\section{REFERÊNCIAS}

ARIÈS, P. História social da infância e da família. Rio de Janeiro: LTC, 1981.

BETTLHEIM, B. A psicanálise dos Contos de Fadas. Tradução de Arlene Caetano. São Paulo: Paz e Terra, 2014.

CORSO, D. L.; CORSO, M. Fadas no Divã: A psicanálise nas histórias Infantis. Porto Alegre: Artmed, 2006.

COSTA, C. N. As Entrelinhas Dos Contos De Fadas: Ponte Para Eternizar Ideologias. 2013. Trabalho de Conclusão de Curso (Curso de Licenciatura em Pedagogia) - Universidade Estadual Paulista, Bauru, 2013.

EGAN, K. Por que a imaginação é importante na educação? In: FRITZEN, C; CABRAL, G. S. (org.). Infância: imaginação e educação em debate. Campinas: Papirus, 2007. p. 11-37.

FLICK, U. Introdução à Pesquisa Qualitativa. Tradução de Joice Elias Costa. 3. ed. Porto Alegre: Artmed Editora, 2009.

FREITAS, M. T. A perspectiva sócio-histórica: uma visão humana da construção do conhecimento. In: FREITAS, M. T.; JOBIM \& SOUZA, S.; KRAMER, S. Ciências humanas e pesquisa: leituras de Mikhail Bakhtin. São Paulo: Cortez, 2007, p. 2139.

GIRARDELLO, G. Imaginação: arte e ciência na infância. Pro-Posições, Campinas, v. 22, n. 2, p. 75-92, maio/ago. 2011.

GIRARDELLO, G. Voz, presença e Imaginação: A narração de histórias e as crianças pequenas. In: FRITZEN, C.; CABRAL, G. S. (org.). Infância: imaginação e educação em debate. Campinas: Papirus, 2007. p. 39-58. 
KIRCHOF, E. R.; SILVEIRA, R. M. H. O pato, a morte e a tulipa - Leitura e discussão de um livro ilustrado desafiador com alunos dos anos iniciais. Educação em Revista, Curitiba, v. 34, n. 72, p. 57-76, dez. 2018.

LAPLANCHE, J.; PONTALIS, J. B. Vocabulário de psicanálise. São Paulo: Martins Fontes, 1985.

LINS, M. J. S. da C. Maturidade Ética e Identidade Moral: a construção na prática pedagógica. Revista Diálogo Educacional, Curitiba, v. 9, n. 28, p. 633-649, set./dez. 2009.

LUDKE, M.; ANDRÉ, M. Pesquisa em Educação: abordagens qualitativas. São Paulo: EPU, 1986.

MAIA, A. C. B.; LEITE, L. P.; MAIA, A. F. O emprego da literatura na educação infantil: a investigação e intervenção com professores de pré-escola. Revista Psicopedagogia, São Paulo, v. 28, n. 86, p. 144-155, 2011.

MASSUIA, C. S. Os contos de fadas e as práticas educativas: o uso do gênero em uma escola municipal de Presidente Prudente. 2011. Dissertação (Programa de Pós-graduação Stricto Sensu em Educação) - Universidade Estadual Paulista, Presidente Prudente, 2011.

MORENO, W. L. Psicodrama. 13. ed. São Paulo: Editora Pensamento Cultrix, 1975.

OLIVEIRA, P. S. T. A contribuição dos contos de fadas no processo de aprendizagem das crianças. 2010. Monografia (Graduação em Pedagogia) Universidade do Estado Da Bahia, Salvador, 2010.

PANIAGUA, G.; PALACIOS, J. Educação Infantil: resposta educativa à diversidade. Tradução de Fátima Murad. Porto Alegre: Artmed, 2007.

RADINO, G. Contos de Fadas e realidade psíquica: a importância da fantasia no desenvolvimento. São Paulo: Casa do psicólogo, 2013.

RADINO, G.; OLIVEIRA, M. L. de. Entre príncipes e sapos. In: OLIVEIRA, M. L. (org.). (Im)pertinências da educação: o trabalho educativo em pesquisa [online]. São Paulo: Editora UNESP; São Paulo: Cultura Acadêmica, 2009. p.17-43.

RODRIGUES, M. E. A. Quem Conta Um Conto: Os Contos De Fadas E As Narrativas das Crianças de uma Creche de Presidente Prudente/SP. 2010. Dissertação (Programa de Pós-Graduação em Educação) - Universidade Estadual Paulista, Presidente Prudente, 2010.

SILVA, M. V. O. da. O Encantamento dos Contos de Fadas. 2010. Trabalho de Conclusão de Curso (Graduação em Pedagogia) - Universidade Federal do Rio Grande do Sul, Porto Alegre, 2010.

SIQUEIRA, E. M. de L. Literatura sem fronteira: por uma educação literária. 2013. Tese (Doutorado em Letras e Linguística) - Universidade Federal de Goiás, Goiânia, 2013. 
VICENTE, N. R. de A. M. Contos de Fadas Tradicionais: Narrativas Ímpares na Infância. Dissertação (Mestrado em Psicologia Clínica) - Instituto Universitário Ispa, Lisboa, 2010.

\section{Sobre as autoras}

\section{Eliziane Gorete Kielb}

Possui Mestrado interdisciplinar em Ciências Humanas pelo Programa de Pós-Graduação Interdisciplinar em Ciências Humanas da Universidade Federal da Fronteira Sul UFFS (2019) e Graduação em Pedagogia pela mesma universidade (2017). Atualmente é Professora de Educação Infantil e Anos Iniciais na Escola Municipal de Ensino Fundamental Othelo Rosa do Município de Erechim (RS), onde atua desde 2013. Tem experiência na área de Educação e Ciências Humanas. Interessa-se por pesquisas relacionadas à educação, infância, construção identitária, literatura e cinema.

\section{Ivone Maria Mendes Silva}

Doutora em Psicologia Escolar e do Desenvolvimento Humano pela Universidade de São Paulo USP (2013). Graduada em Psicologia pela Universidade Federal de Minas Gerais - UFMG (2004), mestrado em Ciências da Saúde pela Universidade Federal de Minas Gerais - UFMG (2008), mestrado em Educação pelo Centro Federal de Educação Tecnológica de Minas Gerais CEFET/MG (2008). Atualmente cursa pós-doutorado em Educação pela USP e é professora adjunta na Universidade Federal da Fronteira Sul (UFFS), Campus Erechim/RS, onde atua desde 2010 junto aos cursos de licenciatura em Pedagogia, Filosofia e Ciências Sociais. É também professora permanente do Programa de Pós-Graduação Interdisciplinar em Ciências Humanas e do Programa de Pós-Graduação Profissional em Educação da mesma Universidade. 